\title{
A Study to Assess the Utility of Cell Block Morphology and Immuno-Cytochemistry For Improving the Pre-Operative Diagnosis of Nodular Thyroid Lesions
}

\author{
Shruti Mishra ${ }^{1 *}$, Kishore Kumar S. ${ }^{2}$, Saumik Das ${ }^{3}$, Aparajita Samaddar ${ }^{4}$, Nandini Das ${ }^{4}$ and Dipanwita Nag $^{4}$ \\ ${ }^{1}$ Dept of Pathology and Lab Medicine, AIIMS, Bhubaneswar, INDIA \\ ${ }^{2}$ Dept of Hematology and BMT Physician, MIOT International, Chennai, INDIA \\ ${ }^{3}$ Dept of Otorhinolaryngology, Medical College and Hospital, Kolkata, INDIA \\ ${ }^{4}$ Dept of Pathology, Medical College and Hospital, Kolkata, INDIA
}

\begin{abstract}
Background: Thyroid nodules are quite common in the general population of India with increasing incidence of malignancyworldwide. Fine Needle Aspiration [FNA] has been the primary modality of pre-operative diagnosis of such lesions till date. But it has got its own share of fallacies and pit-falls. Cell-block [CB] can be done in the same sitting and it gives the advantage of architectural assessment with easy subjectivity to immuno-cytochemical[ICC] staining.

Material and Methods: FNA was done in all patients and CB was prepared by formalin method. ICC stains were used in cases with provisional diagnosis of malignancy and in all follicular neoplasm cases.SPSS v.20 was used for analysis. Sensitivity and specificity of cell block was calculated. Diagnostic correlation of both FNA and CB with respect tohistopathological examination was done by using student t-test with confidence interval of $95 \%$.

Results: CB showed a correlation coefficient of 0.704 and a p value of 0.0001 while FNA showed a correlation coefficient of .464 and a p-value of .001. So, CB showed a strong positive correlation and a high statistical significance. Cell block helped in diagnosing almost all the cases showing discordance in FNA except that of papillary carcinoma where the cellular yield was poor due to cystic degeneration. Sensitivity of cell block was $89.5 \%$ and Specificity was $96.9 \%$.
\end{abstract}

Conclusions: Cell block is definitely a good ancillary examination for thyroid nodular lesions in addition to FNA. It should be routinely performed in all thyroid cases as it improves the diagnostic yield and accuracyof cytological diagnosis.

Keywords: Thyroid, Fine Needle Aspiration Cytology, Cell Block, Immuno-cytoChemistry

\section{Introduction}

Thyroid disorders are the most common among all the endocrine diseases in India. ${ }^{[1]}$ The term "thyroid nodule" means a well-defined lesion within the parenchyma of the gland which can be differentiated from the surrounding either on palpation or by radiological means e.g. sonography. The prevalence of thyroid nodules is about $8.5 \%$ in the world. ${ }^{[2]}$ Just like most thyroid lesions the nodules are also more common among women. In India the incidence rate is more than compared to the world population with the prevalence being $12.2 \%$ as reported by a recent study. ${ }^{[3]}$ Even though thyroid carcinomas are quite rare with an incidence rate of 8.7 per 1, 00,000 people per year but there seem to be a steady rise in the incidence rate over the years. ${ }^{[4]}$ Hence, it is very important to rule out malignancy whenever a patient presents with a thyroid swelling.

Fine needle aspiration cytology (FNAC) of the thyroid, has gained wide acceptance due to its rapidity and cost- effectiveness in distinguishing neoplastic from nonneoplastic nodules and identifying those patients requiring surgery. ${ }^{[5]}$ However, reporting of thyroid cytology has been subject of much debate for last forty years. Now there is a Bethesda system of thyroid FNA diagnosis. FNA smear is considered satisfactory if 6 or more groups of 10 follicular cells each are present on a minimum of two slides. ${ }^{[6,7]}$ The overall sensitivity, specificity, and accuracy of FNAC technique is $83 \%, 92 \%$ and $95 \%$ respectively. ${ }^{[8]}$

Cell blocks (CBs) are often prepared with FNA material and gives us the architectural details of the lesion in addition to the cellular morphology. The main advantage of the $\mathrm{CB}$ is the potential to produce several serial sections for special stains and other ancillary tests, in particular immunohistochemistry. However, the literature contains few reports on their utility with regard to specific organ sites especially thyroid. ${ }^{[9]}$

This study was taken up to find out if cell block actually helps in improving the preoperative diagnostic accuracy 
and to evaluate the utility of doing an immuno-cytochemical staining on suspected cases of carcinomas. Objectives were to assess the sensitivity and diagnostic specificity of cell block preparation in diagnosis of thyroid lesions in comparison with FNA smears; to assess the reliability and difficulties of cell block assessment and to assess the utility of immunocytochemistry done on cell-block preparations in diagnosis of thyroid carcinomas.

\section{Materials and Methods}

The study was conducted over a period of two years in the Department of Pathology, Medical College and Hospital, Kolkata, after ethical clearance as per the revised Helsinki guidelines.

Sample size was estimated using sample size formula and assuming a sensitivity of $85 \%$ and precision of $10 \%$. The minimum number of samples required for this study was 51 cases but we collected 53 cases as two cases were lost to follow-up. All the patients with undiagnosed thyroid nodules admitted or attending our outdoor were included in the study after due consent. We excluded patients who had already been diagnosed and/or relapsed post treatment.

All the patients who were recruited for the study were subjected to FNA procedure after thorough history was taken and clinical examination was done. FNA was done using 23-25 gauge needle and smears were prepared. Both Papanicolaou and May Grunwald Giemsa [MGG] stains were done for each case. FNA slides were reported as per the Royal College of Pathologists guidelines. Gold standard in our study was the histological examination after thyroidectomy was performed.

CB was made using materials from another pass done by 16-18 gauge needles. We used the formalin method of cell block preparation. The thyroid aspirate was mixed with buffered formalin and left for 24 hours. The sample was then centrifuged for ten minutes at $2500 \mathrm{rpm}$. The supernatant was decanted and the pellet was retrieved from test tube by a spatula. The packed sediment was now wrapped in a filter paper and placed in tissue cassette. It was then subjected to processing like a solid tissue. Then sections were made from cell block and stained with haematoxylin and eosin before examination under microscope. Turnaround time for morphological assessment for cell block was around 48 hours.

All the cases suspected of malignancy were subjected to immuno-cytochemical staining and further analysed. Thyroid function tests were done in all patients and ultrasonography was done prior to FNA procedures.

Results were analysed by using SPSS v20. Descriptive statistics are reported using frequency and percentage for categorical data. The index test was compared with the reference method by using student t-test with confidence interval of $95 \%$. A $p$ value of $<0.005$ was considered as statistically significant.

\section{Results}

The age of the patients recruited in our study ranged from 14 years to 71 years, with maximum patients lying in the range of $21-30$ years. $83 \%$ of cases were females and the rest $17 \%$ were males.

Histopathological examination [HPE] was the gold standard for our study. Surgery was performed in 46 out of 53 cases collected. Two cases were lost in follow-up. There were five cases in which surgery was not performed because the nodule was benign and the size was too small. Excluding the two missing data which were lost to followup, $63 \%$ of the cases were benign and $37 \%$ were malignant. Papillary carcinoma was the most common malignant condition in the study sample. [Table: 1]

No malignant cases were recorded in age below 20 years. Two third cases above 60 years and half of the cases between 51-60 years were malignant, showing a positive correlation between advanced age and malignancy. Benign: Malignant ratio in females was $2: 1$ and in males was $0.8: 1$. This can be attributed to higher incidence of thyroid nodules itself in females. [Chart 1,2]

Malignant conditions presented with larger nodular size mostly with eleven out of nineteen presenting in T3 stage. TNM staging was employed in this study. Six were in stage $\mathrm{T} 2$ and one was in T1 stage. One anaplastic carcinoma was in stage T4 as it had involved the trachea also.

Thyroid function tests were done in all patients and it was found that most of the malignant cases had a normal TSH level. Two were in the low normal range and three in the high normal range. Extreme ranges were seen only in benign conditions.

Ultrasonography showed a correlation of 0.172 which is positive but weak. P-value of ultrasonography on paired t-test was 0.226 which was again weak.

FNA was interpreted in broadly four categories. 57\% of cases were diagnosed as benign, $22 \%$ as malignant, six as follicular neoplasm and in rest five smears were unsatisfactory for any interpretation.[Figures 1-6]

A scoring system was followed for assessing the quality of cell block based on cellularity. The scores were: $0=$ No follicular cells; $1=<10$ intact follicles; $2=\geq 10$ intact follicles or tissue fragments. $73 \%$ cases had score $2.23 \%$ cases had a score 1 . Two cases showed no follicular cells. ${ }^{[10]}$ [Chart 3] 
On performing a paired t-test FNA showed a correlation of .464 and a significance of .001. So, FNA is a highly statistically significant test with a positive but not so strong correlation. $\mathrm{CB}$ on the other hand showed a correlation of .704 and a significance of $<0.001$. CB combined with ICC results gave a correlation of $\mathbf{9 1 7}$.So, $\mathrm{CB}$ showed a strong positive correlation and a high statistical significance.
Sensitivity and specificity are characteristics of the test. The population does not affect the results. For calculating sensitivity and specificity we defined true positives, true negatives, false positives and false negatives.

Sensitivity of CB was $89.5 \%$ and specificity of was found to be $96.9 \%$. On the other hand, sensitivity of FNA was $63.16 \%$ and its specificity was $93.75 \%$.

Table 1: Diagnosis on HPE.

\begin{tabular}{|l|l|}
\hline HPE Diagnosis & Frequency \\
\hline Colloid goitre & 10 \\
\hline Adenomatoid goitre & 6 \\
\hline Lymphocytic thyroiditis & 9 \\
\hline Hashimoto's thyroiditis & 3 \\
\hline Papillary carcinoma & 11 \\
\hline Follicular carcinoma & 3 \\
\hline Medullary carcinoma & 2 \\
\hline Anaplastic carcinoma & 3 \\
\hline Follicular adenoma & 2 \\
\hline Grave's disease & 2 \\
\hline Total & 51 \\
\hline NA & 2 \\
\hline Total & 53 \\
\hline
\end{tabular}

Table 2: Discordant cases in FNA.

\begin{tabular}{|l|l|}
\hline FNA Diagnosis & $\underline{\text { HPE Diagnosis }}$ \\
\hline Colloid Goitre (5) & $\begin{array}{l}\text { Adenomatoid Goitre (1) } \\
\text { Lymphocytic thyroiditis (2) } \\
\text { Papillary Carcinoma (2) }\end{array}$ \\
\hline Adenomatoid Goitre (3) & $\begin{array}{l}\text { Hashimoto's Thyroiditis (1) } \\
\text { Papillary Carcinoma (2) }\end{array}$ \\
\hline Anaplastic Carcinoma & Medullary Carcinoma \\
\hline Follicular Neoplasm (6) & $\begin{array}{l}\text { Follicular Carcinoma (3) } \\
\text { Follicular Adenoma (2) } \\
\text { Follicular variant of Papillary Carcinoma(1) }\end{array}$ \\
\hline
\end{tabular}

Table 3: Comparison of Previous and Current Study.

\begin{tabular}{|l|l|l|}
\hline Study Name & Cell Block & Utility Described \\
\hline Nassar A. et al. & Milipore technique & $\begin{array}{l}\text { In hypocellular smears } \\
\text { For Immuno-cytochemistry [ICC] } \\
\text { For FISH }\end{array}$ \\
\hline Bizzarro et al & $\begin{array}{l}\text { CD56, } \\
\text { HBME-1, } \\
\text { Galectin-3 }\end{array}$ & $\begin{array}{l}\text { Useful for differentiating Papillary } \\
\text { lesions from Follicular lesions }\end{array}$ \\
\hline Hegazy et al & Morphology & $\begin{array}{l}\text { Cellblock gave } \\
\text { Better architecture } \\
\text { Better morphology } \\
\text { Better cellularity }\end{array}$ \\
\hline
\end{tabular}




\begin{tabular}{|c|c|c|}
\hline Study Name & Cell Block & Utility Described \\
\hline Haltas et al & Morphology & $\begin{array}{l}\text { Cellblock gave a better architecture like } \\
\text { small biopsies }\end{array}$ \\
\hline Orlandi et al & & Did not improve diagnostic yield \\
\hline Present Study & $\begin{array}{l}\text { Morphology } \\
\text { CK19 } \\
\text { CD56 } \\
\text { Calcitonin }\end{array}$ & $\begin{array}{l}\text { Cellblock } \\
\text { - } \quad \text { Improved the sensitivity and } \\
\text { specificity of cytological diagnosis } \\
\text { - CK19 was specific for Papillary } \\
\text { carcinomas } \\
\text { - } \quad \text { CD56 helped pick up Follicular } \\
\text { carcinomas } \\
\text { - Calcitonin helped in Medullary } \\
\text { carcinomas } \\
\text { Cell block reduced the } \\
\text { discordance between cytology and } \\
\text { histopathology reports }\end{array}$ \\
\hline
\end{tabular}

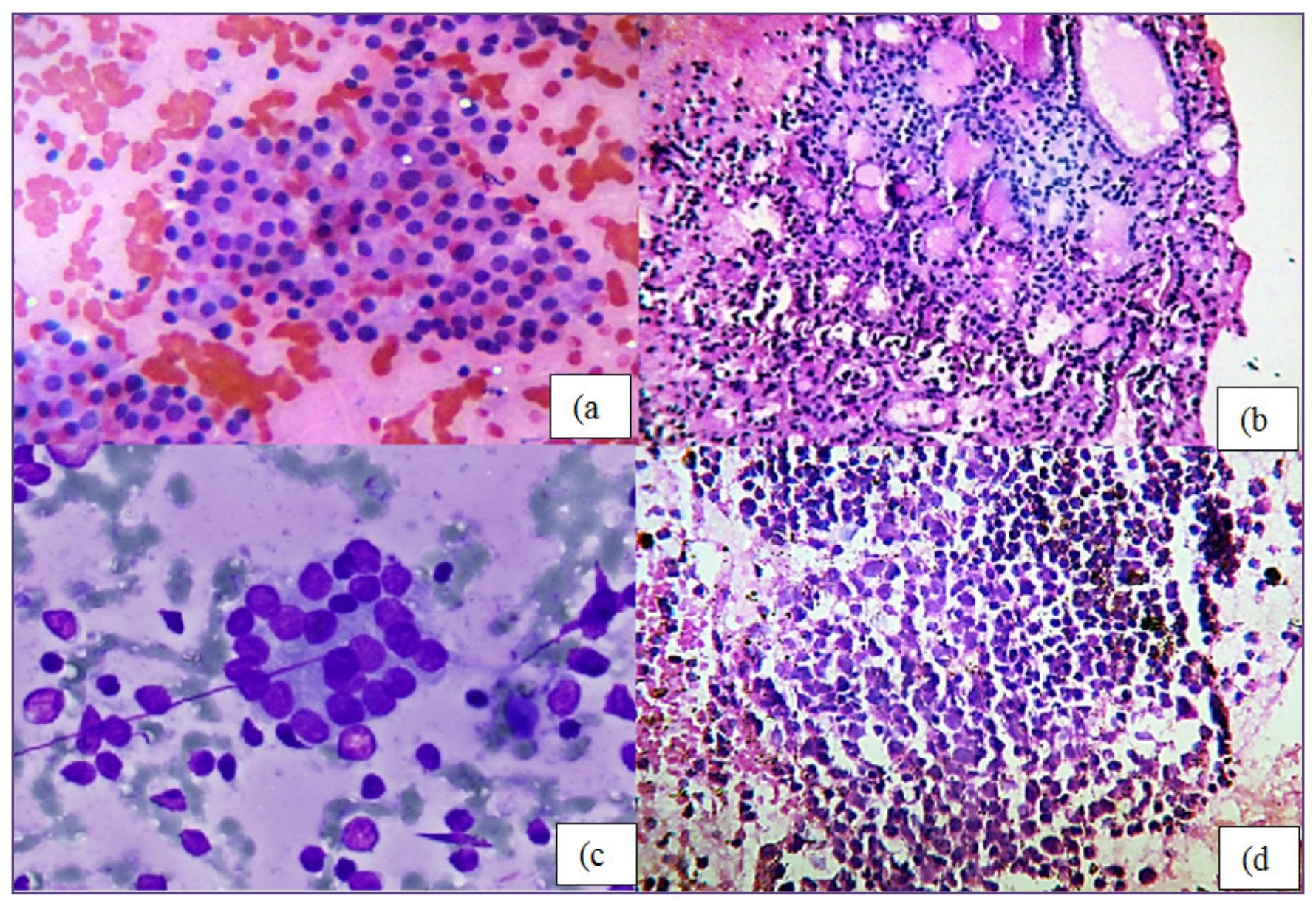

Fig. 1: (a) Large cluster of benign looking follicular cells with thin colloid in the background.[FNA PAP; 100x]; (b) Adenomatoid goitre with multiple follicles. [CB H\&E 100x]; (c) Lymphocytic destruction of follicles. [Lymphocytic thyroiditis] [FNA LG stain 400x]; (d)Lymphocytic thyroiditis with evidence of follicular destruction.[CB H\&E 100x]. 


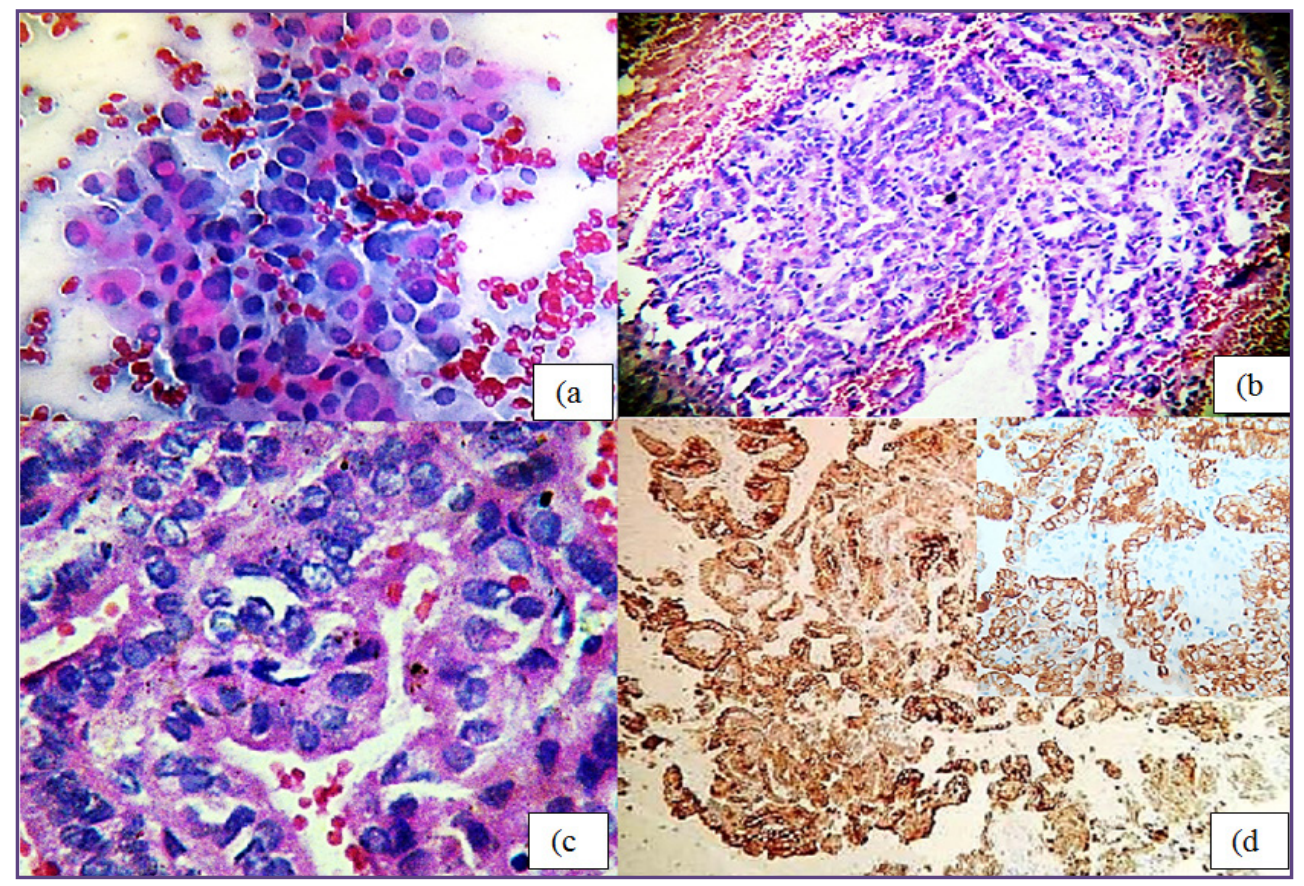

Fig 2: (a) Papillae show nuclear pseudo -inclusions and anisonucleosis. [Papillary carcinoma] [FNA PAP stain 400x]; (b) Section shows numerous papillae. [Papillary carcinoma][CB H\&E 40x]; (c) Papillae lined by cells showing nuclear overlapping, nuclear clearing and grooves of the same case. [Papillary carcinoma][CB H\&E 400x]; (d) Shows strong cytoplasmic membrane positivity of follicular cells lining the papillae. [Inset: Shows strong CK19 cytoplasmic membrane positivity of follicular cells lining the papillae]. [Papillary carcinoma][CK 19 Stained 40x].

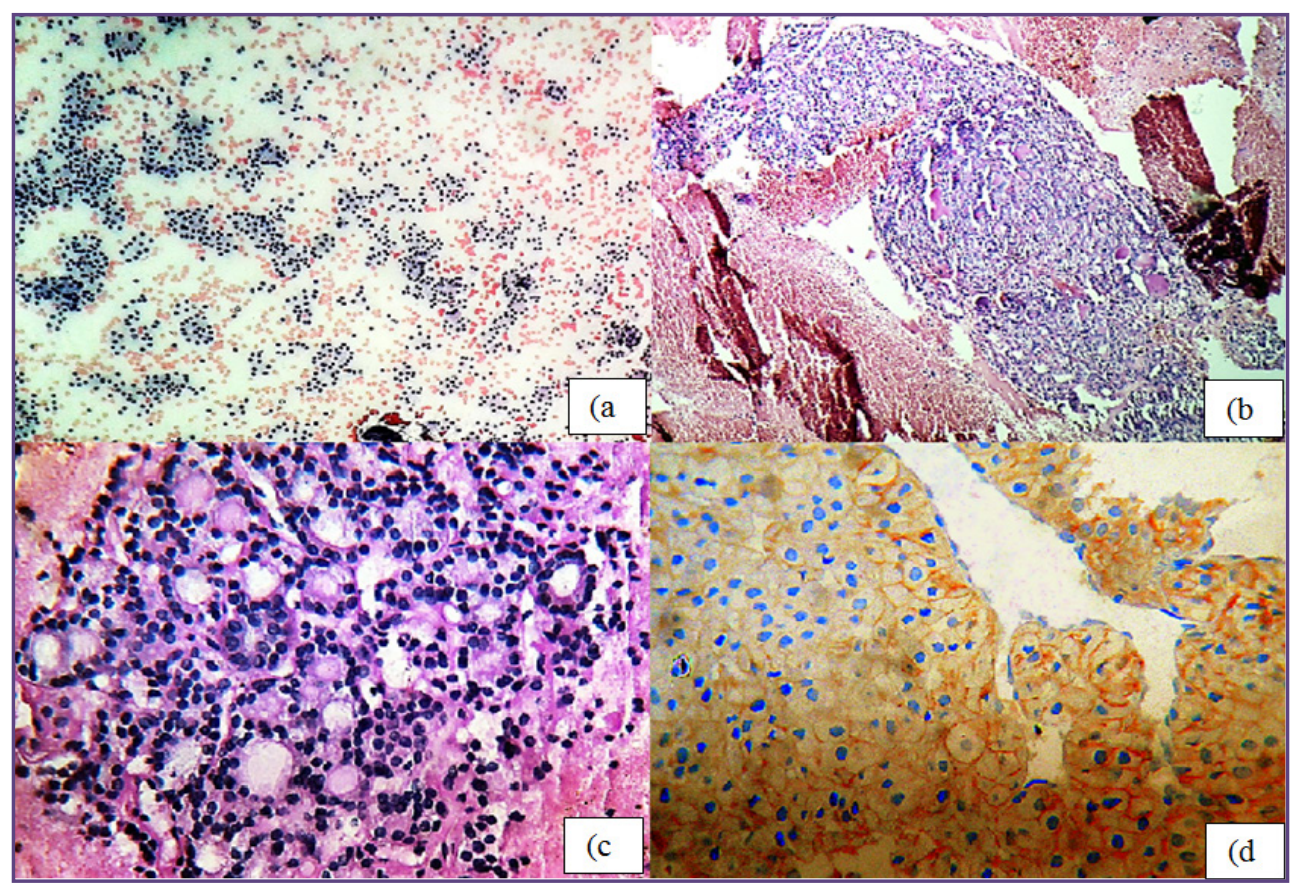

Fig. 3: (a) Shows numerous small follicles in repetitive manner. Follicular cells are uniform. [Follicular neoplasm] [FNA PAP smear 100x]; (b) Clusters of follicles of varying shapes. [Follicular neoplasm] [CB H\&E 40x]; (c) High power view of the above case. [Follicular neoplasm] [CB H\&E 400x]; (d) The cytoplasmic membrane shows positivity indicating that it is a case of follicular carcinoma.[CD56 stain 100x]. 


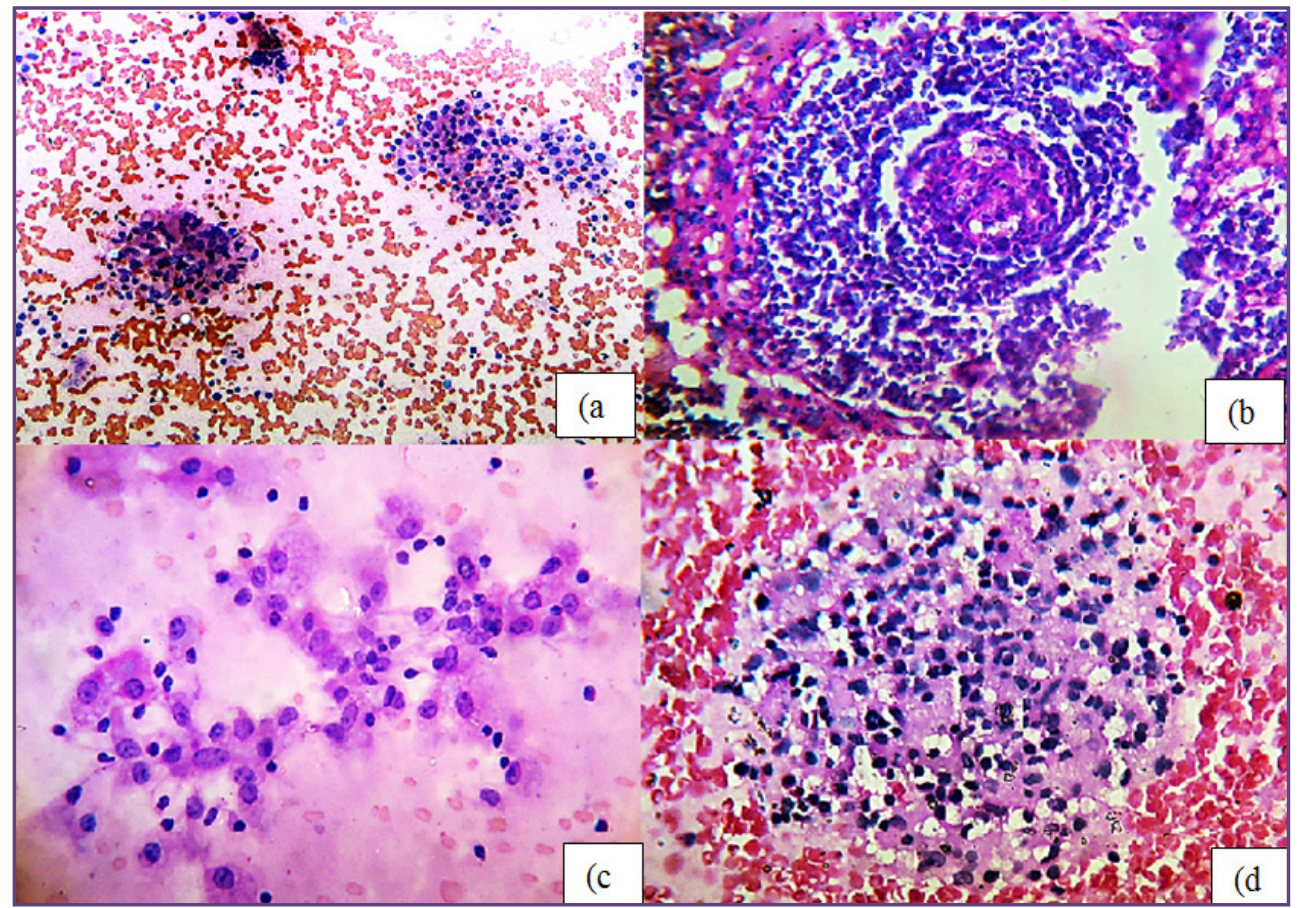

Fig. 4: (a) Smear shows a granuloma on the left and follicular cell collection on the right with Hurthle cell change. [Hashimoto's thyroiditis] [FNA PAP stain 100x]; (b) Shows a well formed granuloma. [Hashimoto's thyroiditis] [CB H\&E stain 400x]; (c) Smear shows Hürthle cells. [FNA Pap stain 100x]; (d) Shows a Hürthle cell changes of follicular cells. [Hashimoto's thyroiditis][CB H\&E stain 400x].

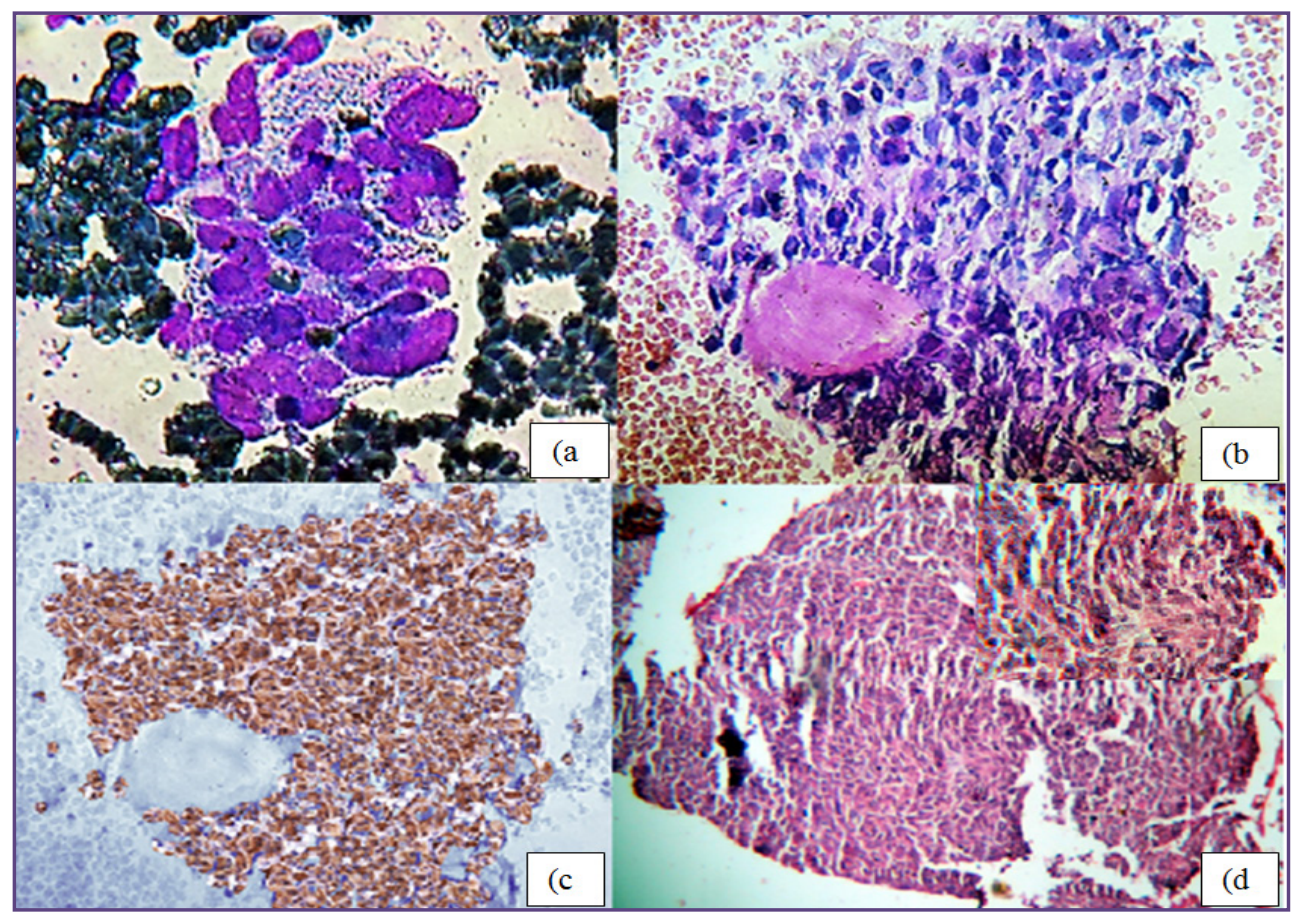

Fig. 5: (a) Clusters of spindle shaped cells. [Medullary carcinoma] [FNA LG stain 400x]; (b) Collection of spindle shaped cells with salt and pepper nucleus and extracellular amyloid collection. [Medullary carcinoma] [CB H\&E 400x]; (c) The cytoplasm of the spindle cells proving that it is a case of Medullary carcinoma. [Calcitonin stains 400x]; (d) Section shows spindle shaped cells with extracellular amyloid. [Inset: Shows 400x view of the same]. [Medullary carcinoma][HP H\&E 100x]. 


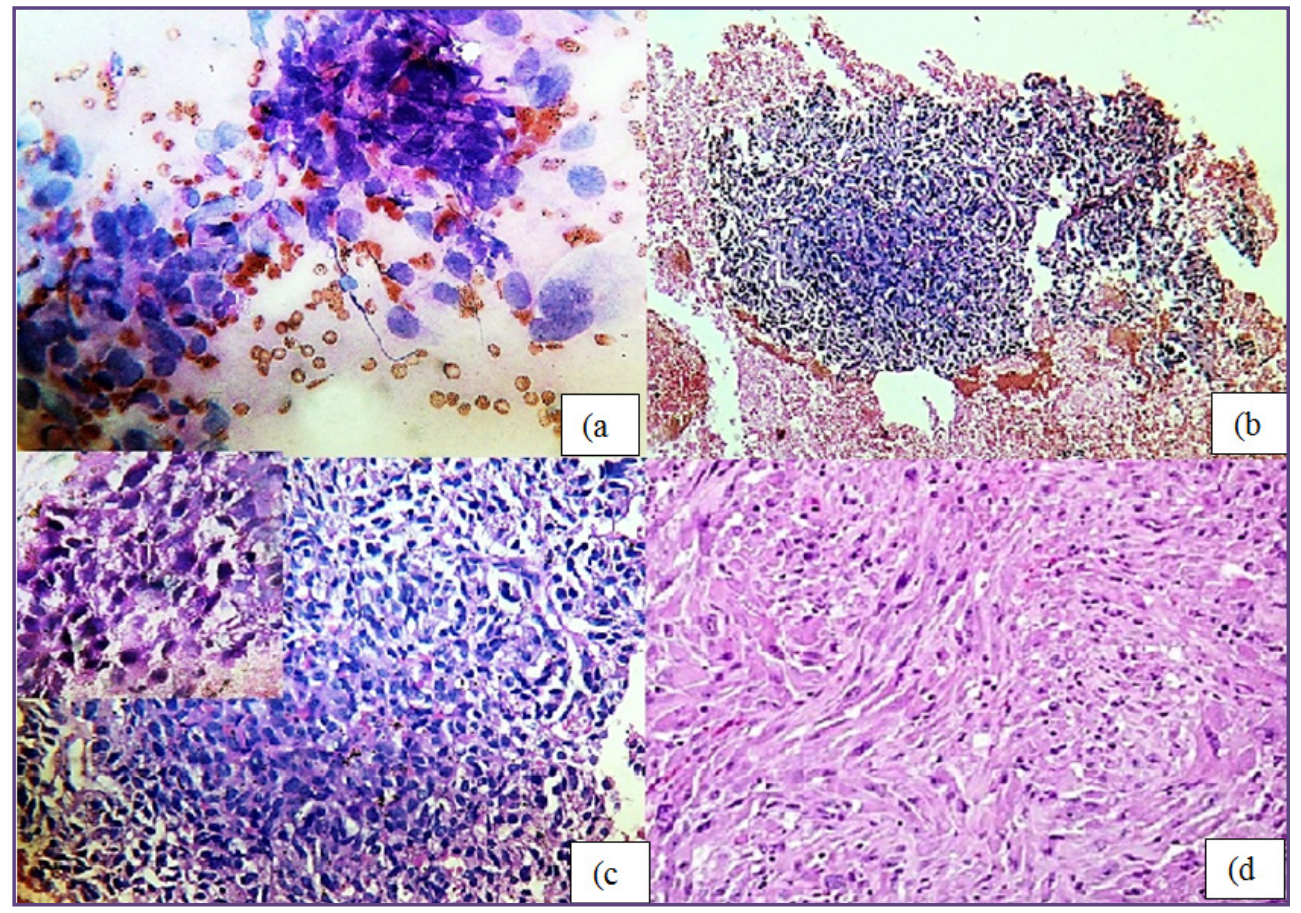

Fig. 6: (a) Shows atypical highly pleomorphic cells. [Anaplastic carcinoma] [FNA PAP stain 400x]; (b) Cluster of atypical and pleomorphic cell collection. [Anaplastic carcinoma] [CB H\&E 40x]; (c) Cluster of atypical and pleomorphic cell collection. Inset shows dysplasia on high power view. [Anaplastic carcinoma] [CB H\&E 100x]; (d) Anaplastic carcinoma.[HP H\&E stain 100x].

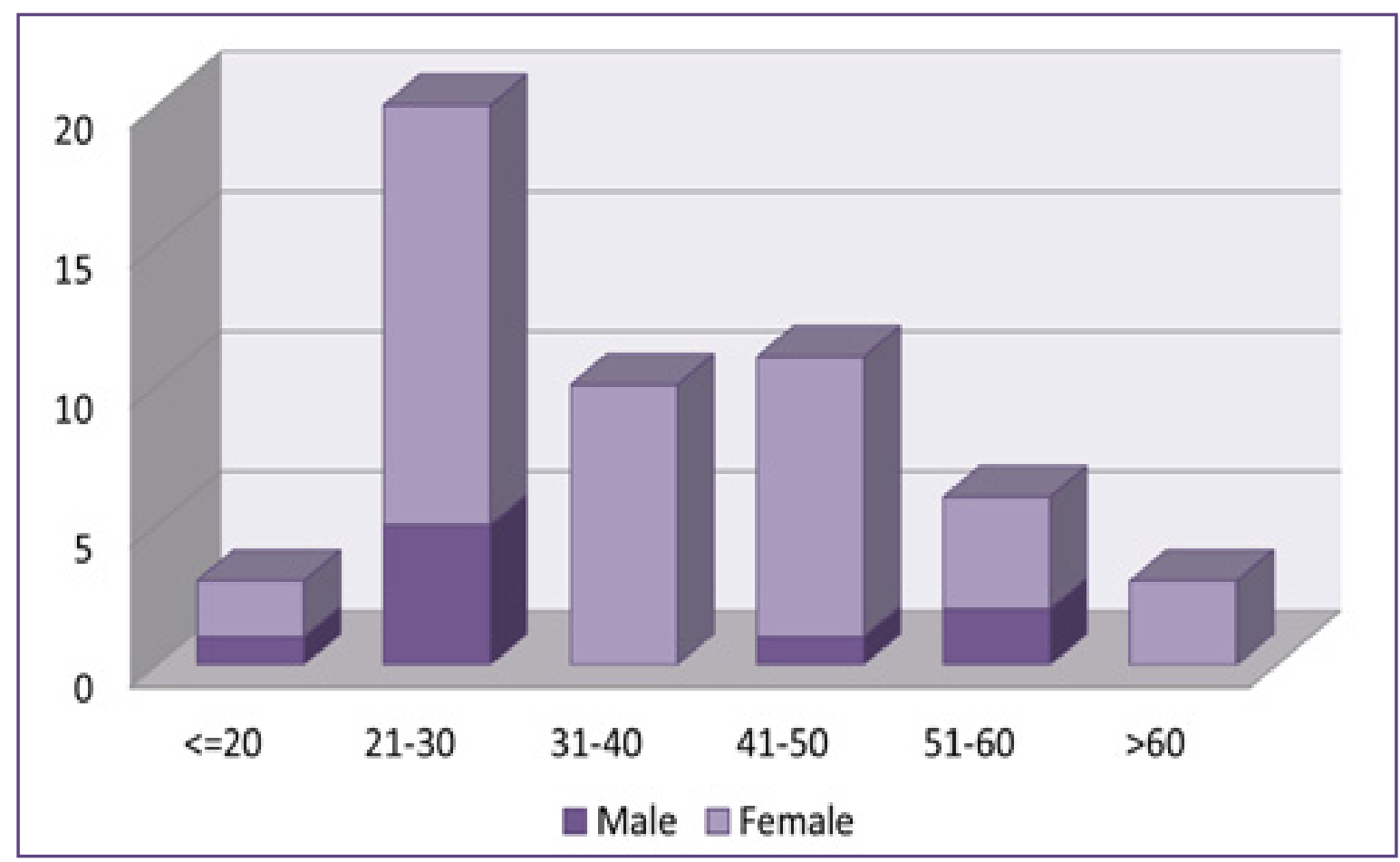

CHART 1: Age-sex distribution in compound bar-charts. 


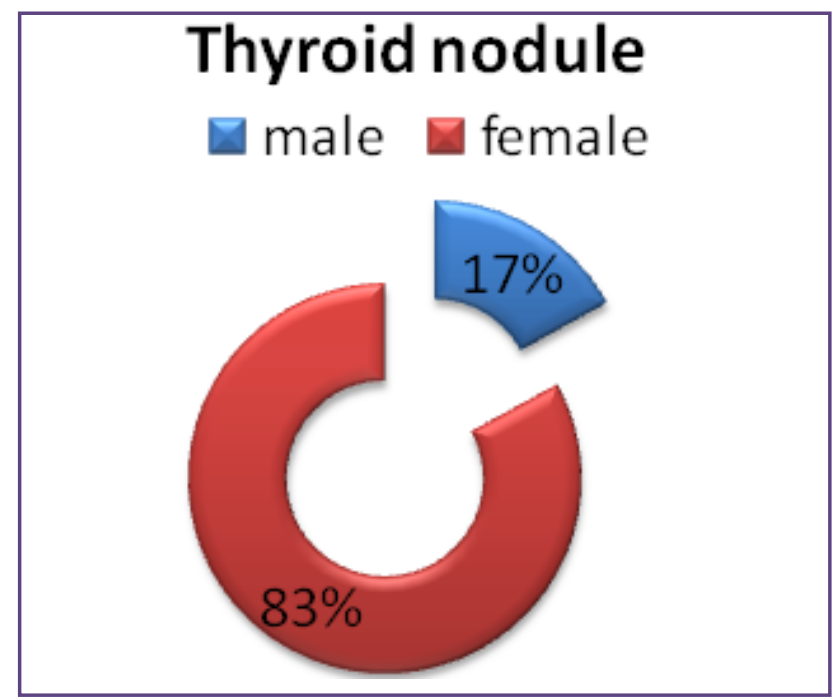

CHART 2: Pie-chart depicting sex frequency.

\section{Discussion}

Thyroid diseases are one of the major burdens in developing countries. Along with the benign lesions there is an increase in world-wide malignant conditions of thyroid. Therefore, an effective test for satisfactory screening of the patients is mandated.

Till date Fine Needle Aspiration or FNA is considered as the gold standard for screening all thyroid nodular lesions. But it has got its own share of fallacies and pit-falls. Sample adequacy and accuracy is highly dependent upon the skills of the pathologist performing the test. Thyroid being an endocrine organ is highly vascular. Therefore the aspirate tends to be haemorrhagic leading to dilution of the aspirate even in the hands of trained professionals and more so when performed by clinicians and radiologists. Also, many a time lesions which have undergone cystic changes are difficult to diagnose as follicular cells are dispersed and are few and far between. Follicular neoplasms are difficult to interpret. Even follicular variant of papillary carcinomas add to the woes of the pathologists.

There are many methods of thyroid reporting. Bethesda system includes five and six category and Royal College of Pathologists follow four category. ${ }^{[11,12]}$ We followed the four category of reporting as it does not include any heading under suspicious for malignancy, which helps in giving a clear cut idea to the clinicians. Satisfactory smears were those which had minimum of 6 intact follicles containing ten follicular cells each.

There is disparity in the literature in the way the cystic lesions are categorized; some categorize all the cystic lesions in unsatisfactory category whereas others do not. ${ }^{[1,12]}$ In our institution, hypocellular aspirates in the

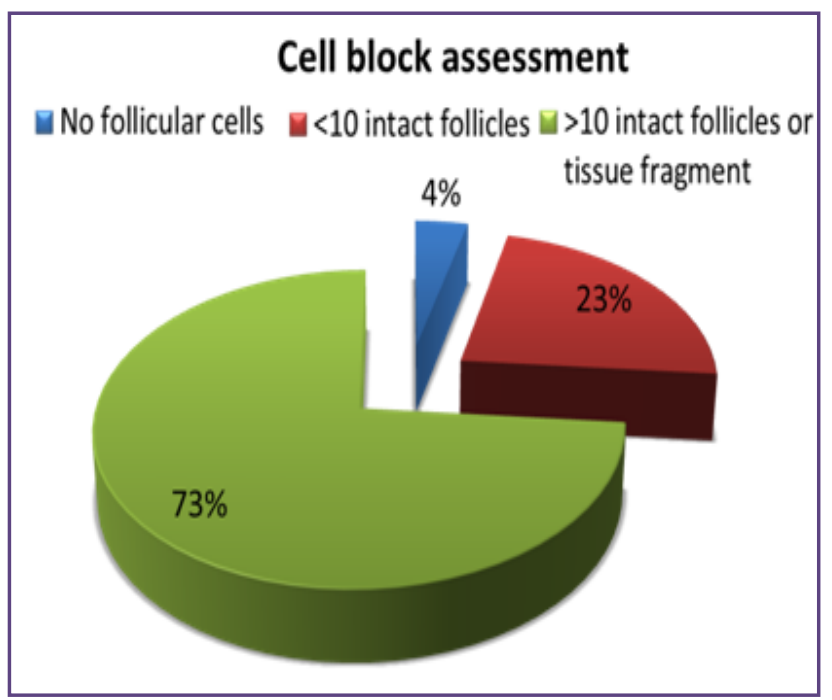

CHART 3: Pie-chart depicting cell block cellularity assessment

presence of cystic fluid are not considered to be nondiagnostic because in these cases the presence of no or a few cells is correlated with the structure of the nodule itself and not with an inadequate sampling technique. We agree with the Royal College guidelines and follow them in our institution because for such lesions if they are labelled as "unsatisfactory" it could imply that the material is not adequate. In such lesions even a repeat sample would be "unsatisfactory". [11]

In our study FNA results showed fifteen discordant cases while the rest were concordant. Most common discrepancy was in exact categorization of the benign lesion and in differentiating follicular adenomas from carcinomas. [Table:2] Previous studies have shown similar concordance and discordance in cases as interpreted by FNA. ${ }^{[13-19]}$

Core needle biopsy or tru-cut biopsies which are usually employed to diagnose lesions in other parts of the body are not usually advised in case of thyroid nodules. Mainly because thyroid being an endocrine organ is highly vascular and can lead to post-biopsy hematomas, bleeding from the incision site, pain, infections, transient hemoptysis, and nerve injuries.

Cell block can be done in the same sitting as that of FNA and this ensures patient compliance and co-operation. There are many different techniques of cell block preparation. The basic idea is to convert aspirated cytological material into a tissue biopsy material which is then embedded in paraffin. Few of the obvious advantages of turning smears into sections are easy storage; further sections can be subjected to special stain and immuno-histochemical staining. In addition to these we get to see the tissue architecture like that of a small biopsy. 
Nassar A. et al. suggested using CBs only in cases where there is the potential for ancillary studies like immunohistochemistry or FISH to be utilized. Milipore Filters $[\mathrm{MF}]$ were recommended for all thyroid FNAs, and if additional cellular residue is available, a CB can also be processed. However, in all cases where hypocellularity was noted at time of initial evaluation of adequacy, a MF only was appropriate. ${ }^{[20]}$

In our study we encountered difficulty in cell block preparation in cases where there was cystic degeneration of the nodules. Two of our cases were unsatisfactory, one being colloid goitre and other being papillary carcinoma. Both the cases had undergone extensive cystic degeneration. FNA in both these cases also showed very poor cellularity but were diagnosed as colloid goitre. Cases having a cell block score of 1 were all benign in nature. Thus, we see that cell block produces a very high yield of cellularity and facilitates morphological analysis on the basis of architecture in malignant cases, only exception being papillary carcinoma which was long standing and had undergone extensive cystic degeneration.

CB showed a correlation coefficient of 0.704 and a significance p-value of .0001 . So, CB showed a strong positive correlation and a high statistical significance. Cell block helped in diagnosing almost all the cases showing discordance in FNA except one papillary carcinoma case where the cellular yield was poor due to cystic degeneration. We had combined the IHC findings with $\mathrm{H} \& \mathrm{E}$ findings of $\mathrm{CB}$ to arrive at the final diagnosis.

Markers done in our study were CK-19, CD-56 and Calcitonin. Cytokeratin 19 marks the membrane of the cells in papillary carcinoma. ${ }^{[21]} \mathrm{CK}-19$ was strongly positive in most of the cases in our study.

Bizzarro et al; suggests that CD56 may be a good marker for ruling out PTC and its variants along with HBME1 and Galectin-3. Their results suggest that CD56 may be a feasible additional marker for identifying thyroid malignancies. ${ }^{[22]}$

In our study out of three cases of follicular carcinoma two gave a strong positivity for CD-56. One was very weakly positive and was taken as negative. Calcitonin was used in suspected cases of medullary carcinoma and it was strongly positive in both our cases.

According to a study by Hegazy et al; cell-block gave a better result than FNAC technique because of good fixation of the specimens as well as good interrelation between the cells. It also reduced the range of inadequacy. The inadequacy of smears was $15 \%$ but cell block reduced it to $(5.8 \%)$. Also, cell-block gave more good interrelation of the cells together, forming follicles or papillae. Also, the nuclear features become more clear and obvious. It was advised to perform cell-block for each case of FNAC of thyroid lesions to decrease the pitfalls and to improve the diagnosis and management of thyroid lesions. ${ }^{[23]}$

In another study by Haltas et al; it was found that benign and malignant follicular cells were observed in both cell block preparations and FNA biopsies. However, thyroid tissue fragments were observed only in the cell block sections similar to the corresponding tissue sections, tissue architecture was apparent in the fragmented tissue section only. ${ }^{[24]}$

In some studies Cell block did not help in the majority of thyroid lesions. In one study, they were contributory in only $25(31 \%)$ of the 82 cases, and of the 23 neoplastic cases, only $5(22 \%)$ CBs were contributory. ${ }^{[25]}$ The contribution of the CBs in the diagnosis of thyroid lesions was minimal because of the low cellularity. On-site assessment of specimen adequacy often results in fewer passes, thus contributing to the low cellularity present in cell-block preparations. ${ }^{[23]}$ [TABLE:3]

\section{Conclusion}

In conclusion our study found that combining ICC findings with the $\mathrm{H} \& \mathrm{E}$ findings of cell blocks were diagnostic in most of the cases. Even they reduced the number of discordant cases produced by FNA. The sensitivity was found to be $89.5 \%$ and specificity was $96.9 \%$. We did not calculate positive and negative predictive values as they are dependent on the prevalence of a disease in the community, while sensitivity and specificity depicts the true diagnostic capacity of a test. Thus, we recommend use of Cell-block along with routine FNA for improving the diagnostic accuracy of thyroid cytology.

\section{Acknowledgement}

We acknowledge all the technical support given by our staff.

\section{Declarations}

- Funding: None

- Competing interests: None declared

\section{Abbreviations}

1. $\mathrm{FNA}(\mathrm{C})$ - Fine Needle Aspiration (Cytology)

2. $\mathrm{CB}-$ Cell Block

3. $\mathrm{H} \& \mathrm{E}$ stain - Haematoxylin and Eosin stain

4. ICC-Immuno-Cytochemistry

5. TSH- Thyroid stimulating hormone

6. FISH- Fluorescence in-situ hybridization

7. MF- Milipore Filters 
8. PTC- Papillary thyroid carcinoma

9. NA - Not Available

\section{References}

1. Mathew J. Burden of Thyroid Diseases in India. Need for Aggressive Diagnosis. Medicine Update, 2008; 18: 334-41.

2. Tunbridge WM, Evered DC, Hall R, Appleton D, Brewis $\mathrm{M}$, Clark F, et al. The spectrum of thyroid disease in a community: The Whickham survey. Clin Endocrinol (Oxf) 1977;7:481-93.

3. Menon UV, Sundaram KR, Unnikrishnan AG, Jayakumar RV, Nair V, Kumar H. High prevalence of undetected thyroid disorders in an iodine sufficient adult south Indian population. J Indian Med Assoc. 2009; 107:72-7.

4. Davies L, Welch HG. Increasing Incidence of Thyroid Cancer in the United States, 1973-2002. JAMA. 2006; 295:2164-7.

5. Mayall F, Chang B, Darlington A. A review of 50 consecutive cytology cell block preparation in a large general hospital. J ClinPathol 1997; 50:985-90.

6. Morgan JL, Serpell JW, Mb BS, Cheng MS, Mb F. Fineneedle aspiration cytology of thyroid nodules: How useful is it? ANZ J Surg. 2003; 73:480.

7. Hamburger JI, Husain M, Nishiyama R, et al. Increasing the accuracy of fine needle biopsy for thyroid nodules. Arch Pathol Lab Med 1989; 113:1035-41.

8. Boey J, Hsu C, Collins RJ. False negative errors in fine needle aspiration biopsy of dominant thyroid nodules: a prospective follow-up study. World J Surg 1986; 10: 623-30.

9. Cooper DS, Doherty GM, Haugen BR, et al. Management guidelines for patients with thyroid nodules and differentiated thyroid cancer: The American Thyroid Association Guidelines Taskforce. Thyroid 2006;16:10942.

10. Mitteldorf C.A.T. S., Vilela R S., Barros A.C., Coudry R.A. Cell block specimens applied to diagnostic routine of thyroid fine-needle aspiration biopsy. J. Bras. Patol. Med. Lab. [Internet]. 2018 Feb [cited 2020 June 17] ; 54 (1): 40-45.

11. Amrikachi M, Ramzy I, Rubenfeld S, Wheeler TM. Accuracy of fine-needle aspiration of thyroid. Arch Pathol Lab Med 2001; 125:484-8.

12. Cross PA, Chandra A, Giles T, Johnson S, Kocjan G, Poller $\mathrm{D}$, Stephenson T. Guidance in the reporting of thyroid cytology specimens 2009 [Internet].
13. Clark $\mathrm{OH}$. Fine-needle aspiration biopsy and management of thyroid tumors. Am J ClinPathol 1997;108(Suppl. 4):S22-5.

14. Smeds $\mathrm{S}$, Lennquist $\mathrm{S}$. The role of aspiration cytology in the management of thyroid nodules. Eur J Cancer Clin Oncol 1988; 24(2):293-7.

15. Ravetto C, Colombo L, Dottorini ME. Usefulness of fine-needle aspiration in the diagnosis of thyroid carcinoma: a retrospective study in 37,895 patients. Cancer 2000; 90:357-63.

16. Sangalli G, Serio G, Zampatti C, Bellotti M, Lomuscio G. Fine needle aspiration cytology of the thyroid: a comparison of 5469 cytological and final histological diagnoses. Cytopathology 2006; 17:245-50.

17. Borgohain R, Lal RK, Chatterjee P, Brahma N, Khanna S. A study of cyto-histological correlation in the diagnosis of thyroid swelling. IOSR J Dent Med Sci 2014; 13(11):46-9.

18. Kumar SK, Seetharamaiah T, Rampure D, Ramakrishna C, Devi RY. Thyroid Nodule: cytohistological Correlation. Scholar J Appl Med Sci 2013; 1:745-7.

19. Sharma C, Krishnanand G. Histologic analysis and comparison of techniques in fine needle aspiration-induced alterations in thyroid. Acta Cytol 2008; 52:56-64.

20. Nassar A, Cohen C., Siddiqui M.T. Utility of Millipore Filter and Cell Block in Thyroid Needle Aspirates: Which Method is Superior? Diagn. Cytopathol. 2007; 35:34-38.

21. Khurana KK, Truong LD, LiVolsi VA, Baloch ZW. Cytokeratin 19 immunolocalization in cell block preparation of thyroid aspirates. An adjunct to fine-needle aspiration diagnosis of papillary thyroid carcinoma. Arch Pathol Lab Med 2003; 127:579-83.

22. Bizzarro T, Martini M, Marrocco C, D'Amato D, Traini E, Lombardi CP, et al. The Role of CD56 in Thyroid Fine Needle Aspiration Cytology: A Pilot Study Performed on Liquid Based Cytology. PLoS ONE 2015; 10(7): e0132939.

23. Sanchez N, Suzanne M. Utility of Cell Blocks in the Diagnosis of Thyroid Aspirates. Diagnostic Cytopathology, 2006; 34: 89-92.

24. Haltaş H., Bayrak R., Yenidünya S., Yildirim U. Diagnostic value of cytokeratin 19, HBME-1, and galectin-3 immunostaining of cell block from fine-needle aspiration specimens in papillary carcinoma of the thyroid. Turk J Med Sci,2013; 43: 625-30

25. Orlandi F., Saggiorato E., Pivano G., et al. Galectin-3 Is a Presurgical Marker of Human Thyroid Carcinoma. Cancer Res 1998; 58:3015-20.

*Corresponding author:

Dr. Shruti Mishra, Plot no 521, Shaheed Nagar, Bhubaneswar- 751007 Odisha, India

Phone: +91 8017377253

Email: msshruti6@gmail.com

Date of Submission : 25/05/2020 